\title{
A FUZZY AHP MULTI-CRITERIA DECISION-MAKING APPROACH APPLIED TO COMBINED COOLING, HEATING AND POWER PRODUCTION SYSTEMS
}

\author{
ANA NIETO-MOROTE* \\ Department of Engineering Projects, Polytechnic University of Cartagena, c/Dr. Fleming, s/n, \\ Cartagena, Murcia 30202, Spain \\ ana.nieto@upct.es \\ FRANCISCO RUZ-VILA \\ Department of Electrical Engineering, Polytechnic University of Cartagena, c/Dr. Fleming, s/n, \\ Cartagena, Murcia 30202, Spain \\ paco.ruz@upct.es
}

Please, cite this article in press as: Nieto-Morote, A, Ruz-Vila, F, A fuzzy AHP multi-criteria decisionmaking approach applied to combined cooling, heating and power production systems, International Journal of Information Technology \& Decision Making, Vol. 10, No. 3 (2011) 497-517. doi: $10.1142 / \mathrm{S} 0219622011004427$

\begin{abstract}
Most of the real-world multi-criteria decision-making (MCDM) problems contain a mixture of quantitative and qualitative criteria; therefore quantitative MCDM methods are inadequate for handling this type of decision problems. In this paper, a MCDM method based on the Fuzzy Sets Theory and on the Analytic Hierarchy Process (AHP) is proposed. This method incorporates a number of perspectives on how to approach the fuzzy MCDM problem, as follows: (1) combining quantitative and qualitative criteria (2) expressing criteria pair-wise comparison in linguistic terms and performance of the alternative on each criterion in linguistic terms or exact values when criterion is qualitative or quantitative, respectively, (3) converting all the assessments into trapezoidal fuzzy numbers, (4) using the difference minimization method to calculate the local weight of criteria, employing the algebraic operations of fuzzy numbers based on the concept of $\alpha$-cuts, (4) calculating the global weight of criteria and the global performance of each alternative using geometric mean and the weighted sum, respectively, (5) using the centroid method to rank the alternatives. Finally, an illustrative example on evaluation of several combined cooling, heat and power production systems is used to demonstrate the effectiveness of the proposed methodology.
\end{abstract}

Keywords: Fuzzy MCDM; AHP; trapezoidal fuzzy numbers; $\alpha$-cuts; CCHP system.

\section{Introduction}

Increasing energy demand, increasing energy cost, energy supply security and environmental concerns are some of the energy-related problems in developed countries. Combined cooling, heating and power (CCHP) systems have been converted in an important option to solve these problems. ${ }^{12}$ CCHP systems not only produce heat and

\footnotetext{
${ }^{*}$ Corresponding author.
} 
electricity but also cooling power, getting a high electrical efficiency, a smooth operation of the plant along the whole year and an improvement of the environmental conditions avoiding the use of CFSs and HCFCs.

In the past, mostly because of economic reasons, CCHP systems were limited to largesized plants. ${ }^{17,20}$ In recent years, there has been an increasing diffusion of various smallscale technologies with a wide range of technical characteristics which, according to what type their prime mover is, are known as: natural gas and diesel internal combustion engine $^{23,}, 34$, stirling engines with water/litium bromide absorption chillers ${ }^{4,}{ }^{27}$; systems with combined vapour compression-absorption refrigeration ${ }^{38}$; or fuel cells ${ }^{30}$. These CCHP systems have been successfully applied by small-users such as hospitals, supermarkets, airports, and hotels. $3.6,30,35,47$

As a consequence of the increasing diffusion of various technologies, the evaluation of CCHP systems has become a crucial issue. The classical evaluation method for CCHP system is single criterion analysis. The thermal economic criteria or economic criteria are often used to evaluate CCHP systems. ${ }^{18}$ However, when decision makers (DMs) judge based on the only criteria the feasibility of a CCHP system, the selection often is inadequate. Technical, economic, social and environmental aspects should be also taken into account by DMs. ${ }^{28}$

The analysis of this problem evaluation suggests that a proper framework for selecting the adequate CCHP system is a multi-criteria decision analysis (MCDA). In simple words, MCDA deals with problem of ranking various alternatives from a finite set of alternatives in the presence of multiple, usually conflicting, criteria.

Some authors have developed specific evaluation method to select CCHP systems. ${ }^{42}$ Pilavachi et al. ${ }^{36}$ proposed the use of a multi-criteria method, based on the elementary sum methods, with an agglomeration function based on the statistical evaluation of weight factors to evaluate 16 kinds of CCHP systems. Technical, economic and social aspects of each system are evaluated in an integrated manner and the results are compared by means of the Sustainability Index. Based on criteria such as overall efficiency, investment cost, fuel cost, electricity cost, heat cost, $\mathrm{CO}_{2}$ production and footprint criteria and depending on the user requirements, the best CCHP system options is established. Alanne et al. ${ }^{2}$ utilized the Preference Assessment by Imprecise Ratio Statements method (PAIRS) to select the optimal CCHP system for a residential building according to financial and environmental performances. Zangeneh et al. ${ }^{46}$ develop an assessment model based on Analytic Hierarchy Process (AHP) for prioritization of distributed generation technologies with respect the economic, technical and environmental attributes and the potential of regional primary energy resource. Wang et al. ${ }^{41}$ presented an improved grey incidence evaluation method for evaluating and comparing five distributed triple-generation systems considering technical, economic, environmental and social aspects. The method adopts the combination of the improved AHP and the entropy information method together with the use of linear combination weighting. Based on the different priority to evaluation indexes, the optimal distributed triple-generation options are established. 
A common characteristic of all these method is to assume complete information and a static deterministic environment. However, in real-world problems of selection of CCHP systems, many problem-solving tasks are too complex to be understood quantitatively. DMs recognize the presence of uncertainty in the estimates of decision parameters, due to unquantifiable information, incomplete information or non-obtainable information. ${ }^{9}$ Therefore, the above mentioned decision methods are not suitable to deal with many realworld problems.

Taking in consideration this problem, only Wang et al. ${ }^{42}$ proposed a hierarchy multiple criteria decision-making (MCDM) model based on Fuzzy Sets Theory to deal with the evaluation and comparison of CCHP systems. In this model, linguistic values are used to assess the ratings of alternatives and weights for evaluation criteria. These linguistic ratings are converted into trapezoidal or triangular fuzzy numbers. According to the concept of the TOPSIS, a closeness coefficient is defined to determine the ranking order of all CCHP systems by calculating the distances to the both fuzzy positive-ideal solution (FPIS) and fuzzy negative-ideal solution (FNIS) simultaneously.

This article presents a MCDM method for selecting the optimal CCHP system according to the end users' requirements appropriated to make decision based on a mixture of quantitative/objective and qualitative/subjective data related to rating of every technology with respect to the specified criteria and relative importance of each criterion to the fulfilment of the overall objective. The proposed method is based on the Fuzzy Sets Theory, that is an effectively tool to deal with subjective judgement, and on the Analytic Hierarchy Process (AHP) which is one of the most extensively used MCDM methods because it does not involve cumbersome mathematics and it is easier to be understood. ${ }^{7}$

\section{Fuzzy AHP}

The AHP method ${ }^{37}$ is a robust and flexible MCDM tool for dealing with complex decision problems. This method divides a complicated system into a hierarchical system of elements, which usually includes objectives, evaluation criteria and alternatives. The evaluation criterion level may be composed of various evaluation criteria which can be also extended into a multi-layer structure. By weighting various evaluation criteria according to the objectives, as well as the alternatives from the viewpoint of each evaluation criterion, the final scores of the alternatives are determined.

The pair-wise comparisons are made of the elements of each hierarchy by means of a nominal scale. Then, comparisons are quantified to establish a comparison matrix, and the eigenvector of the matrix is derived, which signifies the comparative weight amongst various elements of a certain hierarchy. Finally, the eigenvalue is used to assess the strength of the consistency ratio of the comparative matrix and determine whether to accept the information.

The conventional AHP method is a quantitative technique, that is, it does not directly allow the DMs to handle decision problems when they may be uncertain about their level of preference due to incomplete information or knowledge, complexity and uncertainty inherent in the decision environment, or lack of an appropriate measure or scale. In these 
cases, it is easier to determine relative preferences by linguistics values such as "absolutely important, "very strongly important", "essentially important", "weakly important" or "equally important" rather than by specific values of an agreed assessments scale.

As linguistic values are not mathematically operable, a logical way to overcome this limitation is to transform linguistic comparison ratios into fuzzy numbers, that is, each linguistic term is associated with a fuzzy number, which represents the meaning of each generic verbal term.

According to Dubois and Prade ${ }^{16}$ a fuzzy number is a fuzzy set ${ }^{45}$ defined as $A=\left\{x, \mu_{A}\right.$ (x)\} where $x$ takes its number on the real line $\mathbb{R}$ and membership function $\mu_{A}: \mathbb{R} \rightarrow[0,1]$, which have the following characteristics:

(1) A continuous mapping from $\mathbb{R}$ to the closed interval $[0,1]$,

(2) Constant on $(-\infty, \mathrm{a}]: \mu_{A}(x)=0 \forall x \in(-\infty, a]$,

(3) Strictly increasing on $[\mathrm{a}, \mathrm{b}]$

(4) Constant on $[\mathrm{b}, \mathrm{c}]: \mu_{\mathrm{A}}(x)=1 \forall x \in[b, c]$,

(5) Strictly decreasing on $[c, d]$,

(6) Constant on $[d, \infty): \mu_{A}(x)=0 \forall x \in[d, \infty)$,

where, $a, b, c, d$ are real numbers and eventually $a=-\infty$, or $b=c$, or $a=b$, or $c=d$ or $d$ $=\infty$.

For convenience, $\mu_{l A}$ is named as left membership function of a fuzzy number $A$, defining $\mu_{l A}(x)=\mu_{A}(x)$, for all $x \in[a, b] ; \mu_{R A}$ is named as right membership function of a fuzzy number A, defining $\mu_{r A}(x)=\mu_{A}(x)$, for all $x \in[c, d]$.

For the sake of simplicity, trapezoidal or triangular fuzzy numbers are the most commonly used numbers ${ }^{31}$. A trapezoidal fuzzy number $A$ is a fuzzy number denoted as $A=(a, b, c, d)$ which membership function is defined as:

$$
\mu_{A}(x)=\left[\begin{array}{cc}
0 & \text { for } \quad x<a \\
\mu_{l_{A}}(x)=\frac{x-a}{b-a} & \text { for } a \leq x \leq b \\
1 & \text { for } b \leq x \leq c \\
\mu_{r_{A}}(x)=\frac{x-d}{c-d} & \text { for } c \leq x \leq d \\
0 & \text { for otherwise }
\end{array}\right.
$$

where $a, b, c, d$ are real numbers and $a<b<c<d$. If $b=c$, it is defined a triangular fuzzy number.

By the extension principle, the fuzzy arithmetic operations of any two trapezoidal fuzzy numbers $A_{1}=\left(a_{1}, b_{1}, c_{1}, d_{1}\right)$ and $A_{2}=\left(a_{2}, b_{2}, c_{2}, d_{2}\right)$ follow the operational laws for addition, subtraction, multiplication and division of fuzzy numbers:

$$
\begin{gathered}
A_{1} \oplus A_{2}=\left(a_{1}+a_{2}, b_{1}+b_{2}, c_{1}+c_{2}, d_{1}+d_{2}\right) \\
A_{1} \Theta A_{2}=\left(a_{1}-d_{2}, b_{1}-c_{2}, c_{1}-b_{2}, d_{1}-a_{2}\right) \\
A_{1} \otimes A_{2} \approx\left(a_{1} \cdot a_{2}, b_{1} \cdot b_{2}, c_{1} \cdot c_{2}, d_{1} \cdot d_{2}\right) \\
A_{1} \oplus A_{2} \approx\left(a_{1} / d_{2}, b_{1} / c_{2}, c_{1} / b_{2}, d_{1} / a_{2}\right)
\end{gathered}
$$


The fuzzy addition or the fuzzy subtraction of any two fuzzy trapezoidal fuzzy numbers is also trapezoidal fuzzy number. However the fuzzy multiplication or the fuzzy division is only approximate trapezoidal fuzzy number, therefore another formulation of fuzzy multiplication and fuzzy division operations based on the concept of $\alpha$-cut ${ }^{22}$ of a fuzzy number is proposed.

Since the $\alpha$-cut of fuzzy number $A$ is a closed interval of real numbers defined as

$$
A^{\alpha}=\left\lfloor A_{l}^{\alpha}, A_{r}^{\alpha}\right\rfloor=\left\{x \mid \mu_{A}(x) \geq \alpha, \quad 0 \geq \alpha \geq 1\right\}
$$

and any fuzzy number $A$ can fully and uniquely be represented by the standard fuzzy union of its $\alpha$-cuts as

$$
A=\bigcup_{\alpha \in[0,1]}^{\alpha \cdot A^{\alpha}(x)}
$$

it is possible define arithmetic operations on fuzzy numbers in terms of arithmetic operations on closed intervals.

Therefore, the multiplication and division operations of any two positive fuzzy numbers $A$ and $B$, which $\alpha$-cuts are denoted as $A^{\alpha}=\left[A^{\alpha}{ }_{l}, A^{\alpha}{ }_{r}\right]$ and $B^{\alpha}=\left[B^{\alpha}{ }_{l}, B^{\alpha}{ }_{r}\right]$ respectively, can be expressed as:

$$
\begin{array}{r}
A \otimes B=\bigcup_{\alpha \in[0,1]} \alpha \cdot\left(\left[A^{\alpha}{ }_{l} \times B^{\alpha}{ }_{l,} A^{\alpha}{ }_{r} \times B^{\alpha}{ }_{r}\right]\right) \\
A O B= \\
\alpha \in[0,1]
\end{array}
$$

The first fuzzy extensions of the AHP method were worked out by Van Laarhoven and Pedrycz ${ }^{40}$, Buckley ${ }^{5}$, and $\mathrm{Chang}^{8}$, where relative preferences were described by means of fuzzy numbers with triangular membership functions $A=(a, b, d)$. In the process of pairwise comparisons of criteria importance, the DMs express their preferences giving a value of "about b", and uncertainty towards the precision of such a statement is expresses in the form of section length $[a, d]$. In consequence, the judgment matrix includes entries in the form of triangular fuzzy members. In order to find estimators of the fuzzy ratios Van Laarhoven and Pedrycz apply the logarithmic squares method and the fuzzy number arithmetic. Having minimized the logarithmic squares sum, the authors obtain so-called normal equations for the fuzzy case. The set of equations has usually one or more degrees of freedom. In consequence, there does not be a unique solution of the normal equation set. Buckley employs the geometric mean method to calculate the fuzzy weights for each fuzzy matrix, and these are combined in the usual manner to determine the final fuzzy weights for the alternatives. And Chang obtains the estimates for the vectors of weights under each criterion, by using the extent analysis method and by applying the principle of comparison for fuzzy numbers. 
In the fuzzy extension of the AHP method, the procedure of determining weights or calculating vectors of priorities on the basis of pair-wise comparison matrices is a complex computational problem. Among the methods used to solve this problem there are: entropy concepts $^{11}$, Lambda-Max method ${ }^{14}$, eigenvector method ${ }^{19}$ and fuzzy preference programming ${ }^{33}$.

All the aforementioned works compute fuzzy priorities based on arithmetic operations for fuzzy triangular (or trapezoidal) numbers. To be able to use fuzzy arithmetic operations, specific assumptions on the forms of membership functions are required. To date, there are only a limited number of membership-function forms that are computationally manageable. Moreover, the accuracy of the final ranking is inevitably weakened by the series of approximations required during the computation procedure. But the most important criticism on these works has to be their failure to address the issue of consistency $^{10,25}$. There were no explicit articulation on what would constitute as an inconsistent comparison matrix within the fuzzy AHP context and, equally important, on how inconsistent information should be handled.

This paper presents a fuzzy AHP methodology which most significant difference with the above methods is the use of an algorithm to handle the inconsistencies in the fuzzy preference relation when pair-wise comparison judgements are necessary.

\section{Proposed Multi-Criteria Decision-Making Model}

A MCDM problem involves $\mathrm{m}$ alternatives evaluated on $\mathrm{n}$ criteria. Thus, the judgment matrix can be modeled as:

$$
G=\left[G_{i j}\right]_{m \times n}=\begin{gathered}
C_{1} \\
A_{1} \\
A_{2} \\
\ldots \\
A_{m}
\end{gathered}\left[\begin{array}{cccc}
G_{11} & G_{12} & \ldots & G_{1 n} \\
G_{21} & G_{22} & \ldots & G_{2 n} \\
\ldots & \ldots & \ldots & \ldots \\
G_{m 1} & G_{m 2} & \ldots & G_{m n}
\end{array}\right]
$$

And the weight vectors are:

$$
W=\left[W_{1}, W_{2}, \ldots, W_{n}\right]
$$

$A_{1}, A_{2}, \ldots, A_{m}$ are the possible alternatives which are evaluated, $C_{l}, C_{2}, \ldots, C_{n}$ are the criteria against performance of alternatives are measured, $G_{i j}(i=1,2, \ldots, m ; j=1,2, \ldots, n)$ is the performance of the alternative $A_{i}$ on criteria $C_{j}$ and $W_{j}$ is the related weight of $C_{j}$.

A total utility value of each alternative must be obtained to ranking them. In general, the alternative with the highest utility should be selected as the best one.

In this paper, the MCDM problem will be resolved using the following steps: 
(1) Identify decision criteria. Almost all of the decision-making problems are MCDM problems, the performance rating of each alternative depends on multiple, usually conflicting, criteria. DM, who will have a high degree of knowledge and previous experience in decision-making problems, has intuitive methods of identifying decision criteria according to the objectives of the problem. Anyway, there are some criteria identification tools as Checklist or Brainstorming. ${ }^{1}$ In most cases, the number of criteria is large and then it is necessary to classify them. Following Keeney and Raiffa $^{21}$ or Saaty ${ }^{36}$ the selected criteria can be structured in a hierarchical manner. More general criteria can be linked with more specific criteria to build the hierarchy. In the top of the hierarchy is an all-embracing objective, followed by the broad development goals, then the more specific objectives, and so on. As many levels of decomposition as be necessary can be incorporated into the hierarchical structure whenever the elements of a given level are mutually independent, but comparable to the elements of the same level and group. The analysis is complete when criteria are specific enough for assessing the alternatives. As a pair-wise comparison method is proposed to assess the relative weights of criteria then, from perspective of judgement consistency, the number of elements in a criteria group for pair-wise comparisons should not be more than seven. ${ }^{38}$

(2) Determine the sets of linguistic scales and corresponding fuzzy numbers. Frequently, it may be extremely difficult to assess the relative importance of criteria pair-wise comparisons or the performance of one alternative on some criteria due to the great uncertainty involved. In these circumstances, DM prefers a linguistic assessment instead of an exact value. One of the key points in fuzzy modelling is to assign the membership functions corresponding to fuzzy numbers that represent vague concepts and imprecise terms expressed often in a natural language. The representation does not only depend on the concept but also on the context in which it is used. Even for similar contexts, fuzzy numbers representing the same concept may vary considerably. When operating with fuzzy numbers, the result of our calculations strongly depend on the shape of the membership functions of these numbers. Less regular membership functions lead to more complicated calculations. Moreover, fuzzy numbers with simpler shape of membership functions often have more intuitive and more natural interpretation. All these reasons cause a natural need of simple approximations of fuzzy numbers that are easy to handle and have a natural interpretation. For the sake of simplicity the trapezoidal or triangular fuzzy numbers are the most common in current applications. As noted in a research study ${ }^{32}$, the problems that arise with vague predicates are less concerned with precision and are more of a qualitative type; thus they are generally written as linearly as possible. Normally it is sufficient to use a trapezoidal representation, as it makes it possible to define them with no more than four parameters. Based on Chen's research study about a numerical approximation system focused on systematically convert linguistic terms to their corresponding fuzzy numbers ${ }^{9}$, the linguistic terms used in this paper and their associated membership function are shown in Table 1. In some cases, assessments of performance of the alternatives on some criterion in monetary/quantitative terms are possible when criterion is objective. Trapezoidal fuzzy number can further represent exact values. ${ }^{26}$, 
${ }^{48}$ For example, the crisp number $\$ 300$ can be represented by fuzzy number $(300,300$, $300,300)$.

Table 1. Linguistic values and its associated fuzzy numbers

\begin{tabular}{ll}
\hline Linguistic values for relative importance & Fuzzy number \\
\hline Absolutely less important (AL) & $(0,0,0,0.2)$ \\
Very strongly less important (VSL) & $(0,0,0.1,0.2)$ \\
Strongly less important (SL) & $(0,0.2,0.2,0.4)$ \\
Weakly less important (WL) & $(0.2,0.35,0.35 .0 .5)$ \\
Equally important (E) & $(0.3,0.5,0.5,0.7)$ \\
Weakly more important (WM) & $(0.5,0.65,0.65,0.8)$ \\
Strongly more important (SM) & $(0.6,0.8,0.8,1)$ \\
Very strongly more important (VSM) & $(0.7,0.9,0.9,1)$ \\
Absolutely more important (AM) & $(0.8,1,1,1)$ \\
& \\
Linguistic values of performance of alternatives & Fuzzy number \\
\hline Very High (VH) & $(0,0,0.1,0.2)$ \\
High (H) & $(0.1,0.25,0.25,0.4)$ \\
Middle (M) & $(0.3,0.5,0.5,0.7)$ \\
Low (L) & $(0.6,0.75,0.75,0.9)$ \\
Very Low (VL) & $(0.8,0.9,1,1)$ \\
\hline
\end{tabular}

(3) Pair-wise compare decision criteria. DM is required to provide their opinion of the relative importance for every criteria pair of the same level and group in the hierarchy structure. These linguistic measures are converted into fuzzy members using Table 1. The following comparison matrix for group $\mathrm{g}$ and level 1 in the hierarchy is obtained:

$$
A_{g l}=\begin{gathered}
r_{1} \\
r_{1} \\
r_{2} \\
\cdots \\
r_{n}
\end{gathered}\left[\begin{array}{cccc}
- & v_{2} & \ldots & \mathrm{r}_{\mathrm{n}} \\
v_{21} & - & \ldots & v_{1 n} \\
\ldots & \ldots & \ldots & \ldots \\
v_{n 1} & v_{n 2} & \ldots & -
\end{array}\right]
$$

where $\mathrm{n}$ is the number of criteria of the group $g$ and level $l$.

As we have mentioned, transitivity is the propriety that is usually accepted to deal with fuzzy preference relations consistency. It represents the idea that the preference value obtained by comparing directly two alternatives should be equal to or greater than the preference value between those two alternatives obtained using an indirect chain of alternatives. It is obvious that a minimum consistency is required, and we have chosen wake transitivity concept as the consistency "border" that expert opinions have to respect. In our problem, weak transitivity is satisfied if:

$$
v_{\mathrm{ij}} \geq \text { "Same", } v_{\mathrm{ik}} \geq " \text { Same" } \Rightarrow v_{\mathrm{jk}} \geq " \text { Same" } \forall \mathrm{i}, \mathrm{j}, \mathrm{k}
$$

(4) Estimate weights of criteria. With the hierarchical weighting method, a criterion is associated with a local weight and a global weight. The local weight of a criterion is 
referred to the weight relative to other criteria at the same group and level, which is to be assessed using the pair-wise comparison process. The global weight of a criterion is referred to the weight relative to all other criteria for the overall objective of the decision problem.

(a) Estimate the local weights of criteria. This problem is solved using classical methods of weighting criteria calculation adapted to operate with trapezoidal fuzzy numbers. In the classical methods, the preference information between criterion $C_{i}$ and $C_{j}$ is reflected in their values $w_{i}$ and $w_{j}$. Then, there exists an explicit function relation between $v^{\prime}{ }_{i j}$ and the values $w_{i}$ and $w_{j}$. By the reciprocal property of preference relation matrix, the following equation has to be satisfied to get a set of $v^{\prime}{ }_{i j}$ with the strongest transitivity restriction (additive transitivity) between pair wise comparisons ${ }^{27}$ :

$$
v^{\prime}{ }_{i j}=0.5 \times\left\lfloor 1+\psi\left(w_{i}\right)-\psi\left(w_{j}\right)\right\rfloor
$$

Where $\psi\left(w_{i}\right)$ can be any non-decreasing function, and $\sum w_{i}=1$. In order to keep the simplicity of the method, if $\psi\left(w_{i}\right)$ is defined as $w_{i}$ then $v^{\prime}{ }_{i j}$ is defined as:

$$
v^{\prime}{ }_{i j}=\frac{w_{i}+\left(1-w_{j}\right)}{2}
$$

In our case, $v^{\prime}{ }_{i j}$ are trapezoidal fuzzy numbers. Then Eq (4.6) is rewritten as:

$$
v_{i j}^{\prime}=\frac{w_{i} \oplus\left(1 \Theta w_{j}\right)}{2}
$$

Where $i$ and $j$ are criteria of group $g$ and level $l$, and $\oplus$ and $\Theta$ represents fuzzy addition and subtraction defined in Eq. (2.2) and (2.3), respectively. The main implication of this method is that the sum of $\mathrm{w}_{i}$ should be now a trapezoidal fuzzy number "around one" that must be defined correctly to get a solution. Due to the fuzziness of the opinions and the wake transitivity restriction considered, we could not find an accurate solution for this problem. The $w_{i}$ could be calculated by minimization of the distance between the $v_{i j}$ obtained directly from the experts, and the value $v^{\prime} i j$ :

$$
\min \left[\sum_{i=1}^{n} \sum_{\substack{j=1 \\ i=1}}^{n} d\left(v^{\prime}{ }_{i j}, v_{i j}\right)\right]
$$

where distance $d$ is defined as: ${ }^{24}$

$$
d\left(v_{i j}^{\prime}, v_{i j}\right)=\left[\int_{0}^{1} t(\alpha) d^{2}\left(v_{i j}^{\prime}, v_{i j}{ }^{\alpha}\right) d \alpha\right]^{1 / 2}
$$


where $\mathrm{t}(\alpha)$ is an increasing function between $[0,1]$ for which $\mathrm{t}(0)=0$ and $\int_{0}^{1} t(\alpha) d \alpha=0.5$ and, using the $\alpha$-cut concept, $d\left(v^{\prime}{ }_{i j}{ }^{\alpha}, v_{i j}{ }^{\alpha}\right)$ can be expressed as:

$$
d^{2}\left(v_{i j}^{,}{ }_{i j}^{\alpha}, v_{i j}^{\alpha}\right)=\left(v_{i j_{l}}^{\prime^{\alpha}-v_{i j l}{ }^{\alpha}}\right)^{2}+\left(v_{i j_{r}}^{{ }^{\alpha}}-v_{i j_{r}}^{\alpha}\right)^{2}
$$

To find an acceptable solution for the problem presented in Eq. (3.8), an approach based on the $\alpha$-cut concept is used. The procedure can be summarized as follows:

- Step 1. Define $\Delta \alpha=$ step length and obtain $\mathrm{T}=(\Delta \alpha)^{-1}$.

- Step 2. Define a trapezoidal number $I=\left(1-\delta_{1}, 1-\delta_{2}, 1+\delta_{2}, 1+\delta_{1}\right)$ with $\delta_{1}>\delta_{2}$ to represent the fuzzy value for the number "one".

- Step 3. Minimize for $\alpha_{1}=1$ the objective function:

$$
\sum_{\substack{\mathrm{i}=1 \\ \mathrm{i}=1}}^{\mathrm{n}} \sum_{\substack{\mathrm{n} \\ \mathrm{i}}} d^{2}\left(\frac{w_{i}^{\alpha_{1}} \oplus\left(I_{i}^{\alpha_{1}} \Theta w_{j}^{\alpha_{1}}\right)}{2}, v_{\mathrm{ij}}^{\alpha_{1}}\right)
$$

with the following restrictions:

$$
\begin{aligned}
& \sum_{1}^{n} w_{i, l}^{\alpha_{1}} \leq I_{l}^{\alpha_{1}} \\
& I_{r}^{\alpha_{1}} \leq \sum_{1}^{n} w_{i, r}^{\alpha_{1}} \\
& w_{i}^{\alpha_{1}}=\left[w_{i, l}^{\alpha_{1}}, w_{i, r}^{\alpha_{1}}\right] \supset[0,1]
\end{aligned}
$$

- Step 4. For $\alpha_{\mathrm{k}}=\alpha_{1}-(\mathrm{k}-1) \cdot \Delta \alpha$, with $\mathrm{k}=2,3, \ldots \mathrm{T}$, minimize the objective function:

$$
\sum_{\substack{\mathrm{i}=1 \\ \mathrm{i}=1}}^{\mathrm{n}=1} \sum^{\mathrm{n}} d^{2}\left(\frac{w_{i}^{\alpha_{k}} \oplus\left(I_{i}^{\alpha_{k}} \Theta w_{j}^{\alpha_{k}}\right)}{2}, v_{\mathrm{ij}}^{\alpha_{k}}\right)
$$

with the following restrictions:

$$
\begin{aligned}
& \sum_{1}^{n} w_{i, l}^{\alpha_{k}} \leq I_{l}^{\alpha_{k}} \\
& I_{r}^{\alpha_{k}} \leq \sum_{1}^{n} w_{i, r}^{\alpha_{k}} \\
& w_{i}^{\alpha_{k}}=\left[w_{i, l}^{\alpha_{k}}, w_{i, r}^{\alpha_{k}}\right] \supset[0,1] \\
& w_{i, l}^{\alpha_{k}}<w_{i, l}^{\alpha_{k-1}}, w_{i, r}^{\alpha_{k}}>w_{i, r}^{\alpha_{k-1}}
\end{aligned}
$$

- Step 5. Using Eq. (2.6) and Eq. (2.7), the fuzzy weights $w_{i .}$ are built. 
(b) Estimate the global weights of criteria. Assume the criterion $C_{i}$ has $t$ upper groups at different level in the criteria hierarchy and $w(j)$ group is the group weight of the $j^{\text {th }}$ upper group which contain the criterion $C_{i}$ in the hierarchy. The final value of criterion $C_{i}$, $W_{i}$, can be derived by:

$$
W_{i}=w_{i} \otimes \prod_{j=1}^{t} w_{\text {group }}^{(j)}
$$

where $i$ is each one of the criteria at the lowest level of the hierarchy.

(5) Define and normalize the judgment matrix. The evaluation criteria are their own characteristics and each data of criteria has its own dimension and distribution, it is difficult to directly compare or operate. As result, the original data evaluation criteria should be dimensionless and unit-free by normalization method.

As $G_{i j}$ is a benefit item:

$$
R_{i j}=\frac{G_{i j}}{G_{j}^{+}}=\left(\frac{g_{i j}^{a}}{g_{j}^{d+}}, \frac{g_{i j}^{b}}{g_{j}^{c+}}, \frac{g_{i j}^{c}}{g_{j}^{b+}}, \frac{g_{i j}^{d}}{g_{j}^{a+}} \wedge 1\right)
$$

As $G_{i j}$ is a cost item, then:

$$
R_{i j}=\frac{G_{j}^{-}}{G_{i j}}=\left(\frac{g_{j}^{a-}}{g_{i j}^{d}}, \frac{g_{j}^{b-}}{g_{i j}^{c}}, \frac{g_{j}^{c-}}{g_{i j}^{b}}, \frac{g_{j}^{d-}}{g_{i j}^{a}} \wedge 1\right)
$$

Where:

$$
\begin{gathered}
G_{j}^{+}=\max \left\{G_{i j} \mid i=1,2, \ldots, m\right\}=\left(g_{j}^{a+}, g_{j}^{b+}, g_{j}^{c+}, g_{j}^{d+}\right) \\
G_{j}^{-}=\min \left\{G_{i j} \mid i=1,2, \ldots, m\right\}=\left(g_{j}^{a-}, g_{j}^{b-}, g_{j}^{c-}, g_{j}^{d-}\right)
\end{gathered}
$$

The normalized judgment matrix is rewritten as

$$
\begin{aligned}
& C_{1} \quad C_{2} \quad \ldots \quad C_{n} \\
& G^{\prime}=\begin{array}{c}
A_{1} \\
A_{2} \\
\ldots \\
A_{m}
\end{array}\left[\begin{array}{cccc}
R_{11} & R_{12} & \ldots & R_{1 n} \\
R_{21} & R_{22} & \ldots & R_{2 n} \\
\ldots & \ldots & \ldots & \ldots \\
R_{m 1} & R_{m 2} & \ldots & R_{m n}
\end{array}\right]
\end{aligned}
$$


(6) Calculate value of performance of each alternative. The more common aggregation operator, generally used to obtain the global performance of each alternative is the weighted sum of criteria values:

$$
\omega\left(A_{i}\right)=\left(W_{1} \otimes R_{i 1}\right) \oplus\left(W_{2} \otimes R_{i 2}\right) \oplus \ldots \oplus\left(W_{n} \otimes R_{i n}\right)
$$

where $\oplus$ and $\otimes$ represent fuzzy addition and fuzzy multiplication defined in Eq. (2.2) and (2.8), respectively.

(7) Defuzzificate fuzzy utility values. Defuzzification of fuzzy numbers is an important procedure for rating alternatives. Defuzzification is the operation of producing a nonfuzzy number, a single value that adequately represents the membership function $\omega\left(A_{i}\right)$. There are several methods proposed for defuzzification process. In this methodology, the centroid method is used according to the requirements for reflecting the real situation.

$$
R\left(A_{i}\right)=\frac{\int_{0}^{1} x \times \omega\left(A_{i}\right)(x) d(x)}{\left.\int_{0}^{1} \omega \omega_{i}\right)(x) d(x)}
$$

where $i$ is the number of alternatives.

The output of the fuzzy decision-making procedure is a final rating of alternatives.

\section{Numerical example.}

Below, an illustrative example on evaluation of several CCHP systems is used to demonstrate that the fuzzy MCDM provides a good evaluation and appears to be more appropriate in the fuzzy environment of human subjective judgment. There are three subsections: (1) problem description, (2) application of fuzzy MCDM, and (3) discussions.

\subsection{Problem description.}

The proposed fuzzy AHP method is used to evaluate the available CCHP systems for a typical residential building. The residential building with a total area about $1000 \mathrm{~m}^{2}$ is characterized by the parameters shown in Table 2 .

According to the residents' requirements, in summer the CCHP system provides cool, hot water and electricity, and in winter the heat, hot water and electricity are provided, while in the transition seasons the residents only need electricity and hot water.

A group of four experts in CCHP systems, from the Technical University of Cartagena, is created to identify the CCHP alternatives and the evaluation criteria and construct the hierarchical structure of criteria. Later, they also evaluate the alternatives and compare the evaluation criteria by consensus.

After preliminary screening, the group of experts proposed five alternatives to be evaluated:

- Alternative 1: Stirling engine (gas fuel) with direct-fired lithium bromide (LiBr) absorption water heater/chiller unit. 
- Alternative 2: Gas turbine combined with LiBr absortion water heater/chiller unit with supplemental gas combustion.

- Alternative 3: Gas engine plus LiBr absorption water heater/chiller unit.

- Alternative 4: Solid oxide fuel cell (SOFC), LiBr absorption water heater/chiller unit with supplemental gas combustion, and exchanger.

- Alternative 5: Separate generation system. All electricity comes from the grid, the cooling and heating load is produced by the direct-fired $\mathrm{LiBr}$ absorption unit with the gas fuel and the hot water is generated by the gas boiler.

In any case, insufficient electricity, cooling or heating load is supplied by the grid directly.

Table 2. Significant parameters of residential building.

\begin{tabular}{|c|c|c|}
\hline \multicolumn{2}{|c|}{ Residents' requirements } & Demand \\
\hline \multicolumn{2}{|l|}{ Hot water } & $46 \mathrm{~kW}$ \\
\hline \multirow{2}{*}{ Electricity } & Electro index for resident & $45 \mathrm{~kW} / \mathrm{m}^{2}$ \\
\hline & Electro-load of whole building & $34 \mathrm{Kw}$ \\
\hline \multirow{3}{*}{\multicolumn{2}{|c|}{ Cooling (only in summer days) }} & $70 \mathrm{~kW}$ during $5 \mathrm{~h}$. \\
\hline & & $65 \mathrm{~kW}$ during $12 \mathrm{~h}$. \\
\hline & & $58 \mathrm{~kW}$ during $7 \mathrm{~h}$. \\
\hline \multicolumn{2}{|c|}{ Heating (only in winter days) } & $52.3 \mathrm{~kW}$ during $24 \mathrm{~h}$. \\
\hline
\end{tabular}

On the other hand, based on actual conditions and some relevant references ${ }^{13,36,42}$, the evaluation parameters identified by the group of experts were categorized into four main groups: technical criteria $\left(\mathrm{C}_{1}\right)$, economical criteria $\left(\mathrm{C}_{2}\right)$, environmental criteria $\left(\mathrm{C}_{3}\right)$ and social criteria $\left(\mathrm{C}_{4}\right)$.

To be efficiently assessed, the criteria were decomposed into sub-criteria that are described in Table 3. The hierarchical structure of criteria generated is shown in Figure 1.

Table 3. Definition of sub-criteria

\begin{tabular}{ll}
\hline \hline Criteria & Description \\
\hline $\mathbf{\nabla}_{\text {Primary energy consumption ratio }\left(\mathrm{C}_{11}\right)}$ & Ratio of consumpt. primary energy to the users' demand energy. \\
${ }^{\Delta}$ Exergy efficiency $\left(\mathrm{C}_{12}\right)$ & Ratio of the benefit exergy to the consumpt. exergy in the system. \\
${ }^{\Delta}$ Control property $\left(\mathrm{C}_{13}\right)$ & The systems or equipments are easy to control. \\
$\boldsymbol{\Delta}_{\text {Maturity }\left(\mathrm{C}_{14}\right)}$ & The technology is developed well. \\
${ }^{\Delta}$ Regulation property $\left(\mathrm{C}_{15}\right)$ & The system is easy to regulate to the load with the users. \\
$\mathbf{\nabla}_{\text {Investment cost }\left(\mathrm{C}_{21}\right)}$ & Include the purchase cost and installation cost. \\
$\mathbf{\nabla}_{\text {Investment recovery period }\left(\mathrm{C}_{22}\right)}$ & How long will the investment be paybacked? \\
$\mathbf{\nabla}_{\text {Total annual cost }\left(\mathrm{C}_{23}\right)}$ & Cost per year of owning an asset over its entire service life. \\
$\boldsymbol{\Delta}_{\text {Net present value }\left(\mathrm{C}_{24}\right)}$ & Standard method for the financial appraisal of long-term project.
\end{tabular}




\begin{tabular}{|c|c|}
\hline $\mathrm{NO}_{\mathrm{x}}$ emission $\left(\mathrm{C}_{31}\right)$ & It causes acid rain. \\
\hline$\nabla_{\mathrm{CO}}$ emission $\left(\mathrm{C}_{32}\right)$ & $\begin{array}{l}\text { It may contribute to the greenhouse effect and global warming. } \\
\text { Table } 3 \text { (continued) }\end{array}$ \\
\hline $\mathrm{CO}_{2}$ emission $\left(\mathrm{C}_{33}\right)$ & It is the most prominent greenhouse gas in earth's atmosphere. \\
\hline$\nabla^{N}$ Noise $\left(\mathrm{C}_{34}\right)$ & $\begin{array}{l}\text { It isn't a direct environment factor, but it can influence the } \\
\text { people'work or life. }\end{array}$ \\
\hline${ }^{\Delta}$ Advanced performance $\left(\mathrm{C}_{41}\right)$ & $\begin{array}{l}\text { The technology is advanced now and will be improved in the } \\
\text { future. }\end{array}$ \\
\hline${ }^{\Delta}$ Maintenance convenience $\left(\mathrm{C}_{42}\right)$ & The system or equipments are maintained conveniently. \\
\hline${ }^{\mathbf{\Delta}}$ Safeguards $\left(\mathrm{C}_{43}\right)$ & The system is safe to surrounding and people. \\
\hline Footprint $\left(\mathrm{C}_{44}\right)$ & Space needs. \\
\hline
\end{tabular}

Note: $\boldsymbol{\Lambda}_{=}$benefit item and $\mathbf{\nabla}=$ cost item

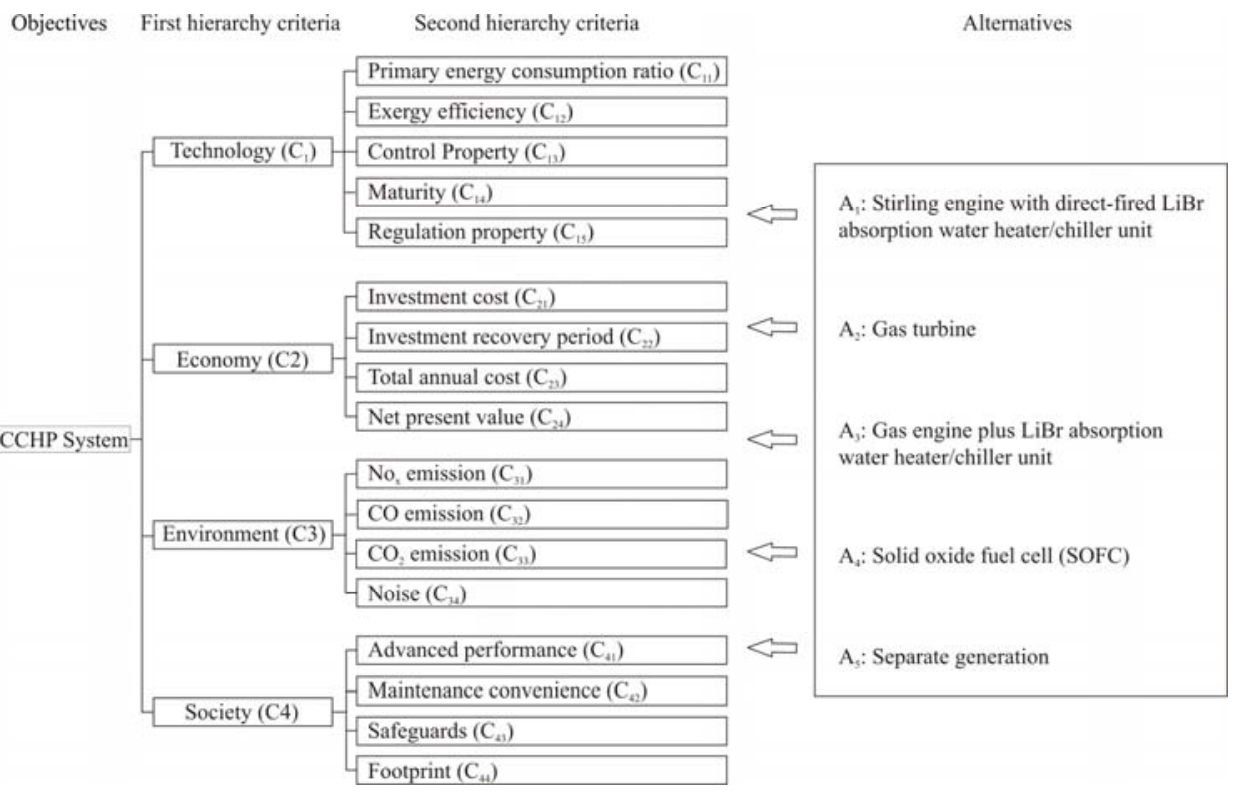

Fig. 1. Hierarchical structure of criteria.

\subsection{Application of fuzzy MCDM method}

Once alternatives and evaluation criteria have been identified, the processes of evaluating the priority of the CCHP systems can be expressed as follows:

(1) Pair-wise comparison of evaluation criteria. Linguistic rating set defined in Table 1 is employed to establish the relative importance for every criteria pair of the same level 
and group in the hierarchical structure defined. These linguistic measures are converted into fuzzy members by the defined membership function according to Table 1. Table 4 summarizes the pair-wise comparison for the first level of hierarchy criteria. In Table 5, the relative fuzzy importance degrees of the criteria of each one of the four groups in the second level of the hierarchy criteria are shown.

Table 4. Pair-wise comparison for the first hierarchy criteria

\begin{tabular}{ccccc}
\hline & $\mathrm{C}_{1}$ & $\mathrm{C}_{2}$ & $\mathrm{C}_{3}$ & $\mathrm{C}_{4}$ \\
\hline $\mathrm{C}_{1}$ & - & $\mathrm{SL}$ & $\mathrm{E}$ & $\mathrm{VSM}$ \\
$\mathrm{C}_{2}$ & $\mathrm{SM}$ & - & $\mathrm{WL}$ & $\mathrm{WM}$ \\
$\mathrm{C}_{3}$ & $\mathrm{E}$ & $\mathrm{WM}$ & - & $\mathrm{SL}$ \\
$\mathrm{C}_{4}$ & $\mathrm{VSL}$ & $\mathrm{WL}$ & $\mathrm{SM}$ & - \\
\hline
\end{tabular}

Table 5. Pair-wise comparison for the second hierarchy criteria of $\mathrm{C}_{1}, \mathrm{C}_{2}, \mathrm{C}_{3}$ and $\mathrm{C}_{4}$

\begin{tabular}{|c|c|c|c|c|c|c|c|c|c|c|c|c|c|c|c|}
\hline $\mathrm{C}_{1}$ & $\mathrm{C}_{11}$ & $\mathrm{C}_{12}$ & $\mathrm{C}_{13}$ & $\mathrm{C}_{14}$ & $\mathrm{C}_{15}$ & $\mathrm{C}_{2}$ & $\mathrm{C}_{21}$ & $\mathrm{C}_{22}$ & $\mathrm{C}_{23}$ & $\mathrm{C}_{24}$ & $\mathrm{C}_{3}$ & $\mathrm{C}_{21}$ & $\mathrm{C}_{22}$ & $\mathrm{C}_{23}$ & $\mathrm{C}_{24}$ \\
\hline $\mathrm{C}_{11}$ & - & WM & WM & SM & WM & $\mathrm{C}_{21}$ & - & VSL & WL & VSL & $\mathrm{C}_{21}$ & - & VSL & WL & VSL \\
\hline$C_{12}$ & WM & - & SM & VSM & SM & $\mathrm{C}_{22}$ & VSM & - & SM & E & $\mathrm{C}_{22}$ & VSM & - & SM & E \\
\hline $\mathrm{C}_{13}$ & WL & SL & - & WM & $\mathrm{E}$ & $\mathrm{C}_{23}$ & WM & SL & - & SL & $\mathrm{C}_{23}$ & WM & SL & - & SL \\
\hline $\mathrm{C}_{14}$ & SL & VSL & WL & - & WL & $\mathrm{C}_{24}$ & VSM & E & SM & - & $\mathrm{C}_{24}$ & VSM & E & SM & - \\
\hline \multirow[t]{6}{*}{$\mathrm{C}_{15}$} & WL & SL & E & WM & - & & & & & & & & & & \\
\hline & & & & & & $\mathrm{C}_{4}$ & $\mathrm{C}_{41}$ & $\mathrm{C}_{42}$ & $\mathrm{C}_{43}$ & $\mathrm{C}_{44}$ & & & & & \\
\hline & & & & & & $\mathrm{C}_{41}$ & - & E & VSL & VSL & & & & & \\
\hline & & & & & & $\mathrm{C}_{42}$ & E & - & VSL & VSL & & & & & \\
\hline & & & & & & $\mathrm{C}_{43}$ & VSM & VSM & - & E & & & & & \\
\hline & & & & & & $\mathrm{C}_{44}$ & VSM & VSM & $\mathrm{E}$ & - & & & & & \\
\hline
\end{tabular}

(2) Estimation of the local weights of criteria and the global weights of criteria. With the hierarchical weighting method, a criterion is associated with a local weight $\left(w_{i}\right)$ and a global weight $\left(W_{i}\right)$. The local and global weights are shown in Table 6 . The local weight is calculated by difference minimization method, using Eqs. (3.7) and (3.8) and the global weight of each criterion is calculated using Eq. (3.15).

Table 6. Local weight and global weight of criteria.

\begin{tabular}{ll}
\hline \hline Criteria & $\mathrm{w}_{\mathrm{i}}$ \\
\hline $\mathrm{C}_{1}$ & $(0.2,0.3,0.3,0.4)$
\end{tabular}


$\mathrm{C}_{11} \quad(0.16,0.20,0.24,0.3)$

$(0.0320,0.0600,0.0720,0.1200)$

Table 6. (Continued)

\begin{tabular}{llll}
\hline \hline & $\mathrm{C}_{12}$ & $(0.3,0.4,0.45,0.55)$ & $(0.0600,0.1200,0.1350,0.2200)$ \\
& $\mathrm{C}_{13}$ & $(0.02,0.05,0.08,0.11)$ & $(0.0040,0.0150,0.0240,0.0440)$ \\
& $\mathrm{C}_{14}$ & $(0,0.02,0.03,0.05)$ & $(0,0.0060,0.0090,0.0200)$ \\
& $\mathrm{C}_{15}$ & $(0.02,0.05,0.08,0.11)$ & $(0.0040,0.0150,0.0240,0.0440)$ \\
\hline $\mathrm{C}_{2}$ & & $(0.3,0.4,0.4,0.5)$ & \\
& $\mathrm{C}_{21}$ & $(0,0.025,0.05,0.075)$ & $(0,0.0100,0.0200,0.0375)$ \\
& $\mathrm{C}_{22}$ & $(0.36,0.54,0.54,0.68)$ & $(0.1080,0.2160,0.2160,0.3400)$ \\
& $\mathrm{C}_{23}$ & $(0.02,0.045,0.065,0.09)$ & $(0.0060,0.0180,0.0260,0.0450)$ \\
& $\mathrm{C}_{24}$ & $(0.43,0.56,0.56,0.75)$ & $(0.1290,0.2240,0.2240,0.3750)$ \\
\hline $\mathrm{C}_{3}$ & & $(0.08,0.18,0.18,0.28)$ & \\
& $\mathrm{C}_{31}$ & $(0.05,0.1,0.15,0.2)$ & $(0.0040,0.0180,0.0270,0.0560)$ \\
& $\mathrm{C}_{32}$ & $(0.1,0.2,0.25,0.35)$ & $(0.0080,0.0360,0.0450,0.0980)$ \\
& $\mathrm{C}_{33}$ & $(0.58,0.65,0.65,0.8)$ & $(0.0464,0.1170,0.1170,0.2240)$ \\
& $\mathrm{C}_{34}$ & $(0,0.055,0.065,0.1)$ & $(0,0.0099,0.0117,0.0280)$ \\
\hline $\mathrm{C}_{4}$ & & $(0.03,0.13,0.13,0.23)$ & \\
& $\mathrm{C}_{41}$ & $(0,0.05,0.1,0.15)$ & $(0,0.0065,0.0130,0.0345)$ \\
& $\mathrm{C}_{42}$ & $(0,0.05,0.1,0.15)$ & $(0,0.0065,0.0130,0.0345)$ \\
& $\mathrm{C}_{43}$ & $(0.3,0.44,0.44,0.58)$ & $(0.0090,0.0572,0.0572,0.1334)$ \\
& $\mathrm{C}_{44}$ & $(0.3,0.44,0.44,0.58)$ & $(0.0090,0.0572,0.0572,0.1334)$ \\
\hline & & &
\end{tabular}

(3) Definition of judgement matrix. Each criterion has its own dimension and distribution, in any cases an exact value is possible to define the performance of an alternative on a criterion and in other cases only a linguistic value is adequate. In this last case, the linguistic scale defined in Table 1, and the corresponding fuzzy numbers, is used to assess the performance of the alternatives on each criterion. The judgement matrix is shown in Table 7.

Table 7. The features of 5 alternatives of trigeneration system and the normalization (in italic) value of 5 alternatives.

\begin{tabular}{|c|c|c|c|c|c|}
\hline $\begin{array}{l}\text { The } 2^{\text {nd }} \\
\text { hierarchy } \\
\text { criteria }\end{array}$ & $\mathrm{A}_{1}$ & $\mathrm{~A}_{2}$ & $\mathrm{~A}_{3}$ & $\mathrm{~A}_{4}$ & $\mathrm{~A}_{5}$ \\
\hline \multirow[b]{2}{*}{$\mathrm{C}_{11}$} & 1.969 & 1.855 & 1.594 & 1.4 & 13.3 \\
\hline & 0.71 & 0.75 & 0.88 & 1.00 & 0.11 \\
\hline
\end{tabular}


A fuzzy AHP multi-criteria decision-making approach applied to CCHP systems 17

$\begin{array}{cccccc}\mathrm{C}_{12} & 30.1 & 44.18 & 34.35 & 35.97 & 11.8 \\ & 0.68 & 1.00 & 0.78 & 0.81 & 0.27\end{array}$

Table 7 (Continued)

\begin{tabular}{|c|c|c|c|c|c|}
\hline \multirow{2}{*}{$\mathrm{C}_{13}$} & $\mathrm{M}$ & $\mathrm{H}$ & M & $\mathrm{L}$ & M \\
\hline & $M$ & $H$ & $M$ & $L$ & $M$ \\
\hline \multirow{2}{*}{$\mathrm{C}_{14}$} & $\mathrm{H}$ & $\mathrm{H}$ & $\mathrm{H}$ & VL & $\mathrm{VH}$ \\
\hline & $H$ & $H$ & $H$ & $V L$ & $V H$ \\
\hline \multirow{2}{*}{$\mathrm{C}_{15}$} & $\mathrm{H}$ & $\mathrm{H}$ & M & $\mathrm{L}$ & M \\
\hline & $H$ & $H$ & $M$ & $L$ & $M$ \\
\hline \multirow[b]{2}{*}{$\mathrm{C}_{21}$} & 535,000 & 680,000 & 504,568 & $1,580,000$ & 290,000 \\
\hline & 0.54 & 0.43 & 0.57 & 0.18 & 1.00 \\
\hline \multirow{2}{*}{$\mathrm{C}_{22}$} & 6.42 & 6.63 & 4.86 & 8.8 & 6.73 \\
\hline & 0.76 & 0.73 & 1.00 & 0.55 & 0.72 \\
\hline \multirow{2}{*}{$\mathrm{C}_{23}$} & 480,137 & 481,374 & 387,851 & 530,131 & 197,179 \\
\hline & 0.41 & 0.41 & 0.51 & 0.37 & 1.00 \\
\hline \multirow{2}{*}{$\mathrm{C}_{24}$} & 52,582 & 28,108 & 546,633 & $-403,086$ & 32,136 \\
\hline & 0.10 & 0.05 & 1.00 & -0.74 & 0.06 \\
\hline \multirow[b]{2}{*}{$\mathrm{C}_{31}$} & 0.23 & 0.223 & 0.7 & 0.007 & 302 \\
\hline & 0.03 & 0.03 & 0.01 & 1.00 & 0.00 \\
\hline \multirow{2}{*}{$\mathrm{C}_{32}$} & 0.45 & 0.6 & 0.8 & 0.001 & 4 \\
\hline & 0.0022 & 0.0017 & 0.0013 & 1.00 & 0.0002 \\
\hline \multirow{2}{*}{$\mathrm{C}_{33}$} & 400 & 589 & 430 & 362 & 700 \\
\hline & 0.91 & 0.61 & 0.84 & 1.00 & 0.52 \\
\hline \multirow{2}{*}{$\mathrm{C}_{34}$} & 65 & 65 & 80 & 60 & 56 \\
\hline & 0.86 & 0.86 & 0.7 & 0.93 & 1.00 \\
\hline \multirow[b]{2}{*}{$\mathrm{C}_{41}$} & $\mathrm{H}$ & M & $\mathrm{H}$ & $\mathrm{VH}$ & $\mathrm{L}$ \\
\hline & $H$ & $M$ & $H$ & VH & $L$ \\
\hline \multirow{2}{*}{$\mathrm{C}_{42}$} & $\mathrm{H}$ & M & $\mathrm{H}$ & VH & $\mathrm{L}$ \\
\hline & $H$ & $M$ & $H$ & $V H$ & $L$ \\
\hline \multirow{2}{*}{$\mathrm{C}_{43}$} & $\mathrm{H}$ & $\mathrm{H}$ & $\mathrm{H}$ & $\mathrm{VH}$ & $\mathrm{VH}$ \\
\hline & $H$ & $H$ & $H$ & $V H$ & $V H$ \\
\hline \multirow{2}{*}{$\mathrm{C}_{44}$} & 0.03 & 0.03 & 0.05 & 0.02 & 0.06 \\
\hline & 0.67 & 0.67 & 0.4 & 1.00 & 0.33 \\
\hline
\end{tabular}

(4) Ranking alternatives. Once the global weights of criteria have been calculated and the performance of each alternative on each criterion has been assessed, the fuzzy preference value of each alternative, $\omega\left(A_{i}\right)$, is calculated by using Eq. (3.21). The fuzzy number associated to the global performance of each proposed alternative must be 
converted into a crisp preference value $R\left(A_{i}\right)$ to raking the alternatives by using Eq. (3.22). All these values are shown in Table 8.

Table 8. Global performance of alternatives and corresponding rating value.

\begin{tabular}{clcc}
\hline \hline Alternatives & $\omega\left(\mathrm{A}_{\mathrm{i}}\right)$ & $\mathrm{R}\left(\mathrm{A}_{\mathrm{i}}\right)$ & Ranking \\
\hline $\mathrm{A}_{1}$ & $(0.2130,0.5179,0.5717,1.0643)$ & 0.6055 & 3 \\
$\mathrm{~A}_{2}$ & $(0.2110,0.5053,0.5623,1.0342)$ & 0.5911 & 4 \\
$\mathrm{~A}_{3}$ & $(0.3600,0.7663,0.8220,1.4652)$ & 0.8713 & 1 \\
$\mathrm{~A}_{4}$ & $(0.3059,0.7157,0.7868,1.4597)$ & 0.8364 & 2 \\
$\mathrm{~A}_{5}$ & $(0.1407,0.3581,0.4020,0.7681)$ & 0.4280 & 5 \\
\hline
\end{tabular}

\subsection{Discussions}

Under the terms of the 1997 Kyoto Protocol, many governments have agreed to try the effort to reduce greenhouse gas emissions. Consequently, some new governmental regulations have been adopted to encourage the introduction of energy efficiency measures and/or the technical changes, such as the building efficiency standards, tax incentives, and new technologies. CCHP systems have been identified as an important option in attempt to achieve the climate change response objectives.

Following these energy policies, many small-scale users such as residential buildings are constructing CCHP systems to produce electricity, hot water and cool or heat. Therefore a precondition to construct a CCHP system has been a feasibility evaluation of all the possible alternatives because of the various types of CCHP technologies that have been developed in the last few years.

In the proposed study case, according to the residents' requirements of electricity and cooling and heating load, five alternatives have been considered suitable for its application in the residential building: stirling engine, gas turbine, gas engine, SOFC and separate generation system. All these technologies present advantages on the other ones but also disadvantages: Stirling engines are characterized by low noise and emissions and high reliability and also by high cost and low efficiencies; gas turbines by good efficiencies, low emissions and low reliability; gas engine by low capital cost, high reliability good electrical efficiencies, low reliability and high noise and emissions; SOFCs by low noise and emissions, high efficiency and high cost.

Therefore, the selection of the optimal CCHP system is a MCDM problem. Based on actual conditions, technical, economical, environmental and social aspects must be considered in the evaluation of alternatives. In this problem, these generic aspects have been decomposed into 17 decision criteria defining a hierarchical structure.

The relative importance of criteria was measured through pair-wise comparison among them. The results show that technical and economic factors are the most important aspect in the evaluation of CCHP systems decision-making and that exergy efficiency and 
investment recovery period and net present value plays the most important role in these aspects, respectively. In addition, primary energy consumption ratio and $\mathrm{CO}$ and $\mathrm{CO}_{2}$ emissions are the key determinants.

Calculated the utility value of each alternative, the ranking order of the five CCHP systems proposed is Alternative 3, Alternative 4, Alternative 1, Alternative 2, Alternative 5. The best scheme is the mode of gas engine plus $\mathrm{LiBr}$ absorption water heater/chiller unit. The worst is Alternative 5 Separate generation system model. The ranking indexes of Alternative 1 and Alternative 2 are close to 0.6 ; therefore, the two alternatives are almost equivalent. Although the stirling engine is not the best, its improvement will allows to reduce costs, and it is believed that this technology will serve a variety of CCHP applications in the future. On the other hand, the SOFC contributes greatly to environment protection and also in the near future the use of this technology will increase.

\section{Conclusions.}

This study develops a scientific framework for selecting the optimal CCHP system according to the user's requirements. The characteristics of the proposed decision making problem are: (a) a finite number of comparable alternatives (b) multiple criteria for evaluation alternatives (c) non-commensurable units for measuring the performance rating of the alternatives on some criterion. Therefore, classical MCDM methodologies are inadequate to apply in this type of MCDM problems. To handle with uncertainty of information and vagueness of judgements and large number of criteria, a MCDM methodology based on multi-criteria analytic hierarchy process and fuzzy sets theory has been proposed.

Compared with other available methods, the advantages of the proposed method can be summarised: (a) a hierarchical structure of criteria is generated to facilitate the process for assessing the weights of criteria, (b) the comparative judgement of criteria pair-wise are expressed in linguistic terms, (c) the performance value of each alternative on each criterion is defined in exact numerical values or in linguistic terms if the criterion is quantitative or qualitative, respectively, (d) the implemented algorithm, that operate with trapezoidal fuzzy numbers, does not require cumbersome computations.

However, the method is mainly limited by the quality of the information given by the experts and it depends on the consistency concept. It has been chosen the wake transitivity concept as the consistency "border" that opinions of each expert have to comply even considering that it is a "soft" criteria to accept the experts' opinions. Then, if the set of pairwise comparisons of one expert is near the border, it is difficult for the mathematical algorithm to find an acceptable solution, but at the same time, the expert's opinion is not conditioned by a very restrictive transitivity definition.

The proposed method provides a systematic framework for selecting CCHP systems in a fuzzy environment that can be easily extended to the analysis of other decision problems in energy area. Although it is a powerful tool of decision, some aspects could be improved such as: (1) the supplement and development of the evaluation criteria, (2) the development of a model to distinguish experts' competence so that different experts have different 
impacts on the final decision, (3) the selection of fuzzy numbers which represents the meaning of evaluation verbal term, particularizing it to the context of the decision problem.

In addition, another research study will be the application of Fuzzy Set Theory to other classical MCDM models such as ANP and compare results.

\section{References.}

1. A. Ahmed, B. Kayis and S. Amornsawadwatana, A review of techniques for risk management in projects, Benchmarking 14 (2007) 22-36.

2. K. Alanne, A. Salo, A. Saari and S. I. Gustafsson, Multicriteria evaluation of residential energy supply systems, Energy and Buildings 39 (2007) 1218-1226.

3. A. Arteconi, C. Brandoni and F. Polonara, Distributed generation and trigeneration: Energy saving opportunitiesin Italian supermarket sector, Applied Thermal Engineering 29 (2009) $1735-1743$.

4. J. C. Bruno, J. Miquel and F. Castells, Optimization of energy plants including water/lithium bromide absorption chillers, International Journal of Energy Research 24 (2000) 695-717.

5. J. J. Buckley, Fuzzy hierarchical analysis, Fuzzy Set and Systems 17 (1985) 233-247.

6. E. Cardona, P. Sannino, A. Piacentino and F. Cardona, Energy saving in airports by trigeneration. Part II: Short and long term planning for the Malpensa $2000 \mathrm{CHCP}$ plant, Applied Thermal Engineering 26 (2006) 1437-1447.

7. U. Cebeci and D. A. Ruan, A Multi- attribute comparison of Turkish quality consultants by fuzzy AHP, International Journal of Information Technology \& Decision Making 6 (2007) 191207.

8. D. Y. Chang, Applications of the extent analysis method on fuzzy AHP, European Journal of Operational Research 95 (1996) 649-655.

9. S. J. Chen and C. L. Hwang, Fuzzy multiple attribute decision making: methods and applications (Springer-Verlag, 1992)

10. M.F. Chen, G.-H. Tzeng \& T.-I. Tang, Fuzzy MCDM approach for evaluation of expatriate assignments, International Journal of Information Technology \& Decision Making 4 (2005) 277-296.

11. C-H Cheng. Evaluating naval tactical missile systems by fuzzy AHP based on the grade value of membership function, European Journal of Operational Research 96 (1996) 343-350.

12. G. Chicco and P. Mancarella, Distributed multi-generation: a comprehensive view, Renewable and Sustainable Energy Reviews 13 (2009) 535-551.

13. H. K. Chiou and G. H. Tzeng, Fuzzy multiple-criteria decision-making approach for industrial green engineering, Environmental Management 30 (2002) 816-830.

14. R. Csutora, J.J. Buckley, Fuzzy hierarchical analysis: the Lambda-Max method, Fuzzy Sets and Systems 120 (2001) 181-195.

15. W. Dong and H. C. Shah, Vertex methods for computing functions of fuzzy variable, Fuzzy sets and Systems 24 (1987) 65-78

16. D. Dubois and H. Prade, Operations on fuzzy numbers, International Journal of Systems Science 9 (1978) 613-626.

17. J. Hernández-Santoyo and A. Sánchez-Cifuentes, Trigeneration: an alternative for energy savings, Applied Energy 76 (2003) 219-227.

18. W. Jiang -Jiang, Z. Chun-Fa and J. You-Yin, Multi-criteria analysis of combined cooling, heating and power systems in different climate zones in China, Applied Energy 87 (2010) 1247 1259.

19. C. H. Juang and D. H. Lee, A fuzzy scale for measuring weights of criteria in hierarchical structures Proc. IFES, (1991).

20. A. Khaliq, R. Kumar and I. Dincer, Performance analysis of an industrial waste head-based trigeneration system, International Journal of Energy Research 33 (2009) 737-744. 
21. R. L. Keeney and H. Raiffa, Decisions with Multiple Objectives, Preferences and Value Tradeoffs (Wiley, New York 1976).

22. J. K. Klir and B. Yuan, Fuzzy sets and fuzzy logic. Theory and applications (Prentice Hall, New Jersey 1995).

23. X. Q. Kong, R. Z. Wang and X. H. Huang, Energy optimization model for a CCHP system with available gas turbines, Applied Thermal Engineering 25 (2005) 377-391.

24. C. K. Kwong, Y. Chen, K.Y. Chan and X. Luo, A generalised fuzzy least-squares regression approach to modelling relationships in QFD, Journal of Engineering Design 21 (2010) 601613.

25. L.C. Leung and D. Cao, On consistency and ranking of alternatives in fuzzy AHP, European Journal of Operational Research 124 (2000) 102-113.

26. G. S. Liang, Fuzzy MCDM based on ideal and anti-ideal concepts, European Journal of Operational Research 112 (1999) 682-691.

27. G. Longo, A. Gasparella and C. Zilio, Analysis of an absorption machine driven by the heat recovery on an I.C. reciprocating engine, International Journal of Energy Research 29 (2005) $711-722$.

28. H. Lund, F. Hvelplund, K. Ingermann and Ü. KaskJ, Estonian energy system: Proposals for the implementation of a cogeneration strategy, Energy Policy 28 (2000) 729-736.

29. Ma, Z. P. Fan, Y. P. Jiang and J. Y. Mao, A method for repairing the inconsistency of fuzzy preference relations, Fuzzy sets and systems 157 (2006) 20-33.

30. G. G. Maidment and R. M. Tozer, Combined cooling heat and power in supermarkets, Applied Thermal Engineering 22 (2002) 653-665.

31. I. Malico, A. P. Carvalhinho and J. Tenreiro, Design of a trigeneration system using a hightemperature fuel cell, International Journal of Energy Research 33 (2009) 144-151

32. G. Mayor and E. Trillas, On the representation of some aggregation functions in Proc. 16th ISMVL, (Blacksburg 1986) 110-114.

33. L. Mikhailov, Deriving priorities from fuzzy pairwaise comparison judgements, Fuzzy Sets and Systems 134 (2003) 365-385.

34. A. Moran, P. J. Mago and L. M. Chamra, Thermoeconomic modeling of micro-CHP (microcooling, heating, and power) for small commercial applications, International Journal of Energy Research 32 (2008) 808-823.

35. A. Piacentino and F. Cardona, An original multi-objective criterion for the design of small-scale polygeneration systems based on realistic operating conditions, Applied Thermal Engineering 28 (2008) 2391-2404.

36. P. A. Pilavachi, C. P. Roumpeas, S. Minett and N. H. Afgan, Multi-criteria evaluation for CHP system options, Energy Conversion and Management 47 (2006) 3519-3529.

37. T. L. Saaty, The Analytic Hierarchy Process: Planning, Priority Setting, Resource Allocation (McGraw-Hill, New York, 1980).

38. T. L. Saaty TL and M. S. Ozdemir, Why the magic number seven plus or minus two, Mathematical and Computer Modelling 38 (2003) 133-244.

39. Z. G. Sun and K. H. Guo, Cooling performance and energy saving of a compression-absorption refrigeration system driven by a gas engine, International Journal of Energy Research 30 (2006) $1109-1116$

40. P. J. M. Van Laarhoven and W. Pedrycz, A fuzzy extension of Saaty's priority theory, Fuzzy Set and Systems 11 (1983) 229-241.

41. J. J. Wang, Y. Y. Jing, C. F. Zhang, X. T. Zhang and G. H. Shi, Integrated evaluation of distributed triple-generation systems using improved grey incidence approach, Energy 33 (2008) 1427-1437.

42. J. J. Wang, Y. Y. Jing, C. F. Zhang, G. H. Shi and X. T. Zhang, A fuzzy multi-criteria decisionmaking model for trigeneration system, Energy Policy 36 (2008) 3823-3832.

43. M. L. Wang, H. F. Wang and L. Chih-Lung, Ranking fuzzy number based on lexicographic screening procedure, International Journal of Information Technology \& Decision Making 4 (2005) 663-678. 
44. R. R. Yager, On a general class of fuzzy connectives, Fuzzy sets and Systems 4 (1980) 235-242.

45. L. A. Zadeh, Fuzzy sets, Information Control 8 (1965) 338-353.

46. A. Zangeneh, S. Jadid and A. Rahimi-Kian, A hierarchical decision making model for the prioritization of distributed generation technologies: a case study for Iran, Energy Policy 37 (2007) 5752-5763

47. D. Ziher and A. Poredos, Economics of a trigeneration system in a hospital, Applied Thermal Engineering 26 (2006) 680-687.

48. H. J. Zimmermann Fuzzy Set Theory and its Applications (Kluwer Academic Publishers, Boston 2001) 